\title{
Adverse Pregnancy Outcomes Among Women with Prior Spontaneous or Induced Abortions
}

\author{
Michel A Makhlouf, M.D., Ph.D., Rebecca G. Clifton, Ph.D., James M. Roberts, M.D., Leslie \\ Myatt, Ph.D., John C. Hauth, M.D., Kenneth J. Leveno, M.D., Michael W. Varner, M.D., John \\ M. Thorp Jr., M.D., Brian M. Mercer, M.D., Alan M. Peaceman, M.D., Susan M. Ramin, M.D., \\ Jay D. lams, M.D., Anthony Sciscione, D.O., Jorge E. Tolosa, M.D., M.S.C.E., and Yoram \\ Sorokin, M.D. for the Eunice Kennedy Shriver National Institute of Child Health and Human \\ Development Maternal-Fetal Medicine Units Network \\ Department of Obstetrics and Gynecology of the University of Texas Medical Branch, Galveston, \\ TX (M.M.); University of Pittsburgh, Pittsburgh, PA (J.M.R.); University of Cincinnati, Cincinnati, \\ $\mathrm{OH}$ (L.M.); University of Alabama at Birmingham, Birmingham, AL (J.C.H.); University of Texas \\ Southwestern Medical Center, Dallas, TX (K.J.L.); University of Utah, Salt Lake City, UT \\ (M.W.W.); of North Carolina at Chapel Hill, Chapel Hill, NC (J.M.T.); Case Western Reserve \\ University-MetroHealth Medical Center, Cleveland, OH (B.M.M.); Northwestern University, \\ Chicago, IL (A.M.P.); University of Texas Health Science Center at Houston, Houston, TX \\ (S.M.R.); The Ohio State University, Columbus, $\mathrm{OH}$ (J.D.I.); Drexel University, Philadelphia, PA \\ (A.S.); Oregon Health \& Science University, Portland, OR (J.E.T.); Wayne State University, \\ Detroit, MI (Y.S.); and The George Washington University Biostatistics Center, Washington, DC \\ (R.G.C.)
}

\section{Abstract}

OBJECTIVE-To determine whether prior spontaneous (SAB) or induced (IAB) abortions, or the inter-pregnancy interval are associated with subsequent adverse pregnancy outcomes in nulliparous women.

METHODS-We performed a secondary analysis of data collected from nulliparous women enrolled in a completed trial of vitamins $\mathrm{C}$ and $\mathrm{E}$ or placebo for preeclampsia prevention. Adjusted odds ratios for maternal and fetal outcomes were determined for nulliparous women with prior $\mathrm{SABs}$ and IABs as compared to primigravid participants.

RESULTS-Compared with primigravidas, women with one prior SAB were at increased risk for perinatal death (OR 1.5; 95\% CI 1.1-2.3) in subsequent pregnancies. Two or more SABs were associated with an increased risk for spontaneous preterm birth (OR 2.6, 95\% CI 1.7-4.0), preterm PROM (OR 2.9, 95\% CI 1.6-5.3) and perinatal death (OR 2.8, 95\% CI 1.5-5.3). Women with one previous IAB had higher rates of spontaneous preterm birth (OR 1.4, 95\% CI 1.0-1.9) and preterm PROM (OR 2.0, 95\% CI 1.4-3.0). An inter-pregnancy interval less than 6 months after SAB was not associated with adverse outcomes.

Corresponding Author: Michel Makhlouf, Department of Obstetrics and Gynecology, The University of Texas Medical Branch, Galveston, TX, 77555-0587, mimakhlo@utmb.edu, Phone: (409) 772 2545, Fax: (409) 7725297. 
CONCLUSION-Nulliparous women with a history of SAB or IAB, especially multiple SABs, are at increased risk for adverse pregnancy outcomes.

\section{INTRODUCTION}

Spontaneous pregnancy loss before 20 weeks gestation is known to affect $12-14 \%$ of pregnant women $(1,2)$. About 1.2 million pregnancies in the United States are medically or surgically terminated each year, corresponding to 22.4 percent of pregnancies (3), with $40 \%$ performed in nulliparous women. Both spontaneous and induced abortions have been associated with adverse pregnancy outcome in a subsequent pregnancy (4-10), including preterm birth (PTB), pre-eclampsia, low birthweight and operative delivery. The relation of future pregnancy outcomes to the duration of the conception-free interval following a spontaneous or induced abortion is uncertain (11). Improved outcomes with longer intervals were observed in a retrospective study (7), but spontaneous abortions (SABs) and induced abortions (IABs) were not separately analyzed. Some studies showed no effect of the interpregnancy interval $(12,13)$, while others found more favorable outcomes with shorter intervals $(14,15)$. Our hypotheses were that a history of spontaneous or induced abortion is associated with adverse pregnancy outcomes in a subsequent pregnancy, and that among women with history of abortion, a shorter inter-pregnancy interval is also associated with adverse outcomes.

\section{METHODS}

\section{Study population}

We analyzed outcome data of low-risk nulliparous women enrolled in the Eunice Kennedy Shriver National Institutes of Health and Human Development Maternal-Fetal Medicine Units Network randomized controlled trial of vitamins $C$ and $E$ versus placebo daily from 916 weeks' gestation until delivery(16). Recruitment was conducted from July 2003 through February 2008 at 16 clinical centers. Briefly, pregnant women with a viable singleton fetus between 9 weeks 0 days and 16 weeks 6 days gestation were eligible for the primary study. Women with a previous pregnancy that lasted beyond 19 weeks 6 days were ineligible. Women with a systolic blood pressure $135 \mathrm{~mm} \mathrm{Hg}$ or higher, diastolic blood pressure 85 $\mathrm{mm} \mathrm{Hg}$ or higher, proteinuria, or those who were taking or had taken antihypertensive medication were also excluded. Women were also excluded if they had pre-gestational diabetes, were taking anti-platelet drugs or non- steroidal anti-inflammatory agents, had uterine bleeding within the week before recruitment, uterine malformation, serious medical condition, known fetal anomaly or aneuploidy, in vitro fertilization resulting in the current pregnancy, or abuse of illicit drugs or alcohol. Participants were followed until delivery and their outcomes were determined prospectively.

\section{Study groups}

As part of the primary study enrollment, women were asked about past pregnancies in detail including, month, year and outcome. Participants were specifically asked whether the pregnancy ended as a result of spontaneous miscarriage, induced abortion, ectopic or molar 
pregnancy. Patients who were not fluent in English were enrolled by someone fluent in their language and signed a consent form in their language.

For this secondary analysis, participants were categorized to one of three groups: those with no prior pregnancy (primigravid), those with one or more SABs, and those with one or more IABs. Women with a prior ectopic pregnancy, molar pregnancy, or with history of both spontaneous and induced abortions were excluded. Outcomes were analyzed based on the number of prior abortions (one versus more than one).

The effect of inter-pregnancy interval on pregnancy outcomes was analyzed in women with a history of one SAB or one IAB. The inter-pregnancy interval was defined as the time elapsed from date of abortion to last menstrual period of the index pregnancy. Three interpregnancy intervals were analyzed: less than 6 months ( $<183$ days), 6-12 months (183-364 days) and greater than 12 months ( $>365$ days). These intervals were chosen based on those reported in prior studies $(7,15)$.

\section{Study Outcomes}

Study outcomes were collected by trained research staff following pre-specified definitions. Data were collected in a uniform manner across all the study sites on pre-specified forms. Maternal outcomes analyzed were spontaneous preterm birth, indicated preterm birth, preterm PROM and preeclampsia. Spontaneous PTB was defined as a birth occurring at less than 37 weeks 0 days gestation as a result of spontaneous onset of labor or preterm PROM, excluding pregnancies that were lost as a result of $\mathrm{SAB}$ or IAB prior to 20 weeks 0 days. PTBs occurring secondary to maternal or fetal indications (i.e., indicated preterm deliveries) were reported separately from spontaneous PTBs. Fetal and neonatal outcomes included fetal or neonatal death, birthweight less than the 5th percentile for gestational age adjusted by sex and race (17), and admission to the neonatal intensive care unit.

\section{Statistical Analyses}

Categorical variables were compared using the chi-square test and continuous variables using the Kruskal-Wallis test. Multivariable logistic regression analysis was used to calculate odds ratios (OR) and included maternal age, race, education, smoking, marital status, BMI at enrollment, and whether they received placebo or vitamins $\mathrm{C}$ and $\mathrm{E}$ in the randomized trial. A nominal $\mathrm{p}$ value less than 0.05 was considered to indicate statistical significance and no adjustments were made for multiple comparisons. Analyses were performed using SAS software (Cary, NC). The original trial had been approved by the institutional review board at each clinical site and the data coordinating center.

\section{RESULTS}

\section{Study participants}

In the original study (16), 10154 women underwent randomization and 183 were lost to follow up. One subject had data removed at her request and another had data removed at the IRB's request. Therefore, outcomes were available for 9969 nulliparas enrolled in the randomized trial. We excluded 231 women: three were multiparous and erroneously 
enrolled, one died prior to delivery, 88 had a history of ectopic pregnancy, and 139 had a history of both spontaneous and induced abortions. The analyzed groups consisted of 7681 primigravid women, 1060 women with a history of one SAB and 180 women with a history of two or more SABs. There were 642 women with a history of one IAB and 175 subjects with a history of two or more IABs. The demographics are listed in Table 1.

\section{Women with prior SAB}

Compared with primigravid women, women with a history of one SAB were at increased risk for fetal or neonatal death (adj. OR 1.5; 95\% CI 1.1-2.3) (Table 2). Women with 2 or more SABs were at increased risk for spontaneous PTB (adj. OR 2.6, 95\% CI 1.7-4.0), preterm PROM (adj. OR 2.9, 95\% CI 1.6-5.3), perinatal death (adj. OR 2.8, 95\% CI 1.55.3), and birthweight less than the 5th percentile (adj. OR 2.2, 95\% CI 1.3-3.7). The risk for pre-eclampsia and neonatal intensive care admissions were not different in women with a history of one $\mathrm{SAB}$ or two or more SABs compared with primigravid women.

\section{Women with prior IAB}

Compared with primigravidas, women with a history of one IAB were at increased risk for spontaneous PTB (adj. OR 1.4, 95\% CI 1.0-1.9) and preterm PROM (adj. OR 2.0, 95\% CI 1.4-3.0). These risks were not significantly increased in women with two or more IABs. Women with a history of 2 or more IABs had a lower risk of neonatal birthweight less than the 5th percentile (adj. OR 0.2, 95\% CI 0.1-1.0). There was no significant difference in the risk for pre-eclampsia, fetal or neonatal death or neonatal intensive care admissions compared to primigravid women (Table 3).

\section{Effect of inter-pregnancy interval}

Of the 1060 women with a history of one SAB, the inter-pregnancy interval could be determined in 1040. There were 395 women with a SAB-to-pregnancy interval of less than 6 months, 216 with an interval of 6-12 months and 429 with an interval greater than 12 months. Women in the 6-12 months group were at higher risk for preterm PROM (adj. OR 3.7, 95\% CI 1.3-10.3) compared to women with an interval less than 6 months. There was no statistically significant difference in any of the other outcomes compared to women with an interval less than 6 months (Table 4).

In women with a history of a single IAB, inter-pregnancy interval could be determined in 631; 61 women had an IAB-to-pregnancy interval of less than 6 months, 64 had an interval of 6-12 months and 506 had an interval greater than 12 months. There was no statistically significant difference in any of the other outcomes between the groups (data not shown).

\section{COMMENT}

Our secondary analysis identified an increased risk of adverse pregnancy outcomes in low risk women with a history of either spontaneous or induced abortion. A history of one SAB is associated with an increased risk of perinatal death in a subsequent pregnancy. A history of two or more SABs was associated with an increased risk of PTB, perinatal death, and birthweight less than the $5^{\text {th }}$ percentile compared to primigravid women. These findings are 
consistent with previous reports, and raise new questions about pathways that might explain the observed associations.

Bhattacharya et al. (5) found an increased risk of pregnancy complications in women with one prior miscarriage compared to nulliparous women. Hammoud et al. (18) also noted a small increased risk (odds ratio of 1.13) of PTB and PPROM in women with a history of one miscarriage. Our findings are consistent with other studies showing adverse outcomes with increasing number of miscarriages (18-20). The association between SAB and subsequent PTB was also confirmed in a recent meta-analysis (10).

Moreover, the results of our study are consistent with the findings of others reporting an increased risk of adverse outcomes in women with a prior IAB (4,10,21-24). Chen et al found lower odds for preterm delivery in women with one mifepristone abortion compared with women with no abortion (25). Reasons for the association between both spontaneous and induced abortion and subsequent preterm birth are unclear. Women experiencing spontaneous and induced abortion may share risk factors for preterm birth that are currently unknown, or may acquire risk for subsequent preterm birth via the medical care they received that might alter endometrial environment, e.g., antibiotic prophylaxis, duration of cervical dilation, or uterine curettage.

If uterine instrumentation is the common exposure, it is interesting to note that women exposed to fertility evaluation have also been reported to have an increased risk of subsequent preterm birth (26). In our study we do not have data on medical vs. surgical terminations. Unlike multiple SABs, we did not find a statistically significant association between multiple IABs and PTBs or PPROM, although our ability to detect this association may have been limited by our sample size.

Studies examining the association of SAB or IAB with hypertension and pre-eclampsia in a subsequent pregnancy have reported conflicting results (27-31). SAB and IAB were found to be associated with reduced pre-eclampsia risk in some studies $(27,28,30)$, but not others $(30,32)$. Certain studies have shown this association to be dependent on timing of abortion (33) or the woman's parity (28). We did not find an association between prior SAB or IAB and pre-eclampsia. However, our study analyzed women who had no history of hypertension or proteinuria, factors known to be related to subsequent pre-eclampsia. While this may create a selection bias, the advantage to this exclusion is determining the association of prior $\mathrm{SAB}$ or IAB with pre-eclampsia without the confounding effects of hypertensive disorders.

Women with two or more IABs had a reduced risk of SGA infants. Chen et al. (25) reported slightly higher birth weight following mifepristone-induced abortion. Nulliparity is a risk factor for SGA (34) compared to multiparous women. It is possible that the reduced risk for SGA in women with multiple IABs is related to their multigravid status.

The effect of inter-pregnancy interval on pregnancy outcomes following a miscarriage has been controversial (11). A large retrospective study (7) from South America showed improved outcomes with longer intervals, however SABs and IABs were not separately analyzed and the study included multiparous women. In another study evaluating interpregnancy interval after SAB, Goldstein et al found no significant differences in outcomes 
between the immediate or delayed conception groups, however their study population consisted of 64 participants (12). In contrast, a large population-based retrospective study examining pregnancy records in Scotland from 1981 to 2000 found better pregnancy outcomes in nulliparous women who conceived within 6 months of a spontaneous abortion (15).

The SAB sample size for our study yields a power of 0.75 for two sided alpha of 0.05 to detect the PTB rate difference reported previously (7). In the SAB group our study found higher risk for preterm PROM in women whose inter-pregnancy interval was 6-12 months as compared to those with an interval of less than 6 months but the potential biological mechanisms of this observation are unknown. Otherwise, there was no statistically significant association between inter-pregnancy interval and adverse outcomes. Our results do not support recommending a waiting period following miscarriage. One limitation of our study and all other studies addressing inter-pregnancy interval following miscarriage is lack of knowledge whether the women had intentionally waited beyond 6 months or had decreased fertility or other factors compared to those that conceived sooner. Our findings, along those of other investigations, underscore the need for a prospective study to address this question.

Data on the previous type and number of abortions were collected by research personnel in an interview with the study participant, and the medical records of the prior pregnancies were not reviewed. Although abstracting data from medical records is more accurate, our data were obtained specifically on each past pregnancy and by research personnel fluent in the patient's language. While under-reporting of IAB is a known limitation of surveys (35), the net effect of under-reporting would be an apparent decrease in the risk of adverse outcomes in the IAB group. Therefore the risk of adverse outcomes could be potentially higher than what our data have shown.

The strengths of our study include a large cohort, low risk population and well-documented maternal and perinatal outcomes. Additionally, because SAB and IAB data were collected and analyzed in an identical fashion, our findings suggest that the adverse outcomes following multiple SABs are more frequent and more severe than after IAB; in agreement with a recent cohort study from Scotland (36). The discrepancy in outcomes following multiple SABs versus multiple IABs suggests that adverse outcomes following multiple spontaneous abortions are not solely related to pregnancy evacuation.

A possible limitation of our study is the lack of information on gestational age at the time of abortion or of the surgical or medical techniques used in the termination. Higher gestational age at the time of a SAB is associated with worse outcomes in a subsequent pregnancy (3738). Similarly, dilation and evacuation may be associated with worse complications than medically induced abortion (4-25). Finally, it is possible that the multiple comparisons performed could have resulted in spurious findings and apparent associations due to chance. The last of these is made unlikely by the similarity of our observations to previous observational reports. 
Our findings suggest that adverse outcomes in future pregnancies are increased in women with a history of spontaneous or induced abortion even in the absence of medical risk factors. These risks are higher in women with a history of two prior SABs. In contrast, there was no clear association between inter-pregnancy interval and subsequent pregnancy outcome. Large prospective studies specifically intended to discover linkages between spontaneous and induced abortion with preterm parturition and other adverse outcomes are needed to better identify risk factors for subsequent pregnancies in women with prior abortion(s). Nonetheless, our findings may be helpful in the counseling of women with previous spontaneous or induced abortions.

\section{Acknowledgments}

The project described was supported by grants from the Eunice Kennedy Shriver National Institute of Child Health and Human Development (NICHD) [HD34208, HD27869, HD40485, HD40560, HD40544, HD34116, HD40512, HD21410, HD40545, HD40500, HD27915, HD34136, HD27860, HD53118, HD53097, HD27917, and HD36801]; the National Heart, Lung, and Blood Institute; and the National Center for Research Resources [M01 RR00080, UL1 RR024153, UL1 RR024989] and its contents do not necessarily represent the official view of NICHD, NHLBI, NCRR or NIH.

The authors thank Elizabeth Thom, Ph.D., for protocol development, data management and statistical analysis, Sabine Bousleiman, R.N.C., M.S.N., and Margaret Cotroneo, R.N., for protocol development and coordination between clinical research centers, Gail D. Pearson, M.D., Sc.D., for protocol development and oversight, and George Saade, M.D. for manuscript oversight.

\section{References}

1. ANDERSEN A-MN, WOHLFAHRT J, CHRISTENS P, OLSEN J, MELBYE M. Maternal age and fetal loss: population based register linkage study. BMJ. 2000; 320:1708. [PubMed: 10864550]

2. WILCOX AJ, WEINBERG CR, O'CONNOR JF, et al. Incidence of early loss of pregnancy. N Engl J Med. 1988; 319:189-94. [PubMed: 3393170]

3. JONES RK, KOST K, SINGH S, HENSHAW SK, FINER LB. Trends in abortion in the United States. Clin Obstet Gynecol. 2009; 52:119-29. [PubMed: 19407518]

4. ATRASH HK, HOGUE CJ. The effect of pregnancy termination on future reproduction. Baillieres Clin Obstet Gynaecol. 1990; 4:391-405. [PubMed: 2225607]

5. BHATTACHARYA S, BHATTACHARYA S. Effect of miscarriage on future pregnancies. Womens Health (Lond Engl). 2009; 5:5-8. [PubMed: 19102634]

6. BHATTACHARYA S, TOWNEND J, SHETTY A, CAMPBELL D, BHATTACHARYA S. Does miscarriage in an initial pregnancy lead to adverse obstetric and perinatal outcomes in the next continuing pregnancy? BJOG. 2008; 115:1623-9. [PubMed: 18947339]

7. CONDE-AGUDELO A, BELIZÁN JM, BREMAN R, BROCKMAN SC, ROSAS-BERMUDEZ A. Effect of the interpregnancy interval after an abortion on maternal and perinatal health in Latin America. International Journal of Gynecology \& Obstetrics. 2005; 89:S34-S40. [PubMed: 15820366]

8. MARTIUS JA, STECK T, OEHLER MK, WULF KH. Risk factors associated with preterm $(<37+0$ weeks) and early preterm birth $(<32+0$ weeks): univariate and multivariate analysis of 106345 singleton births from the 1994 statewide perinatal survey of Bavaria. Eur J Obstet Gynecol Reprod Biol. 1998; 80:183-9. [PubMed: 9846665]

9. MOREAU C, KAMINSKI M, ANCEL PY, et al. Previous induced abortions and the risk of very preterm delivery: results of the EPIPAGE study. BJOG. 2005; 112:430-7. [PubMed: 15777440]

10. SWINGLE HM, COLAIZY TT, ZIMMERMAN MB, MORRISS FH. Abortion and the risk of subsequent preterm birth: a systematic review with meta-analyses. J Reprod Med. 2009; 54:95108. [PubMed: 19301572]

11. BHATTACHARYA S, SMITH N. Pregnancy following miscarriage: what is the optimum interpregnancy interval? Womens Health (Lond Engl). 2011; 7:139-41. [PubMed: 21410339] 
12. GOLDSTEIN RRP, CROUGHAN MS, ROBERTSON PA. Neonatal outcomes in immediate versus delayed conceptions after spontaneous abortion: a retrospective case series. Am J Obstet Gynecol. 2002; 186:1230-4. discussion 34-6. [PubMed: 12066103]

13. WYSS P, BIEDERMANN K, HUCH A. Relevance of the miscarriage-new pregnancy interval. J Perinat Med. 1994; 22:235-41. [PubMed: 7823264]

14. BASSO O, OLSEN J, CHRISTENSEN K. Risk of preterm delivery, low birthweight and growth retardation following spontaneous abortion: a registry-based study in Denmark. Int J Epidemiol. 1998; 27:642-6. [PubMed: 9758119]

15. LOVE ER, BHATTACHARYA S, SMITH NC, BHATTACHARYA S. Effect of interpregnancy interval on outcomes of pregnancy after miscarriage: retrospective analysis of hospital episode statistics in Scotland. BMJ. 2010; 341:c3967. [PubMed: 20688842]

16. ROBERTS JM, MYATT L, SPONG CY, et al. Vitamins C and E to prevent complications of pregnancy-associated hypertension. N Engl J Med. 2010; 362:1282-91. [PubMed: 20375405]

17. ALEXANDER GR, KOGAN MD, HIMES JH. 1994-1996 U.S singleton birth weight percentiles for gestational age by race, Hispanic origin, and gender. Matern Child Health J. 1999; 3:225-31. [PubMed: 10791363]

18. HAMMOUD AO, MERHI ZO, DIAMOND M, BAUMANN P. Recurrent pregnancy loss and obstetric outcome. Int J Gynaecol Obstet. 2007; 96:28-9. [PubMed: 17196203]

19. JIVRAJ S, ANSTIE B, CHEONG YC, FAIRLIE FM, LAIRD SM, LI TC. Obstetric and neonatal outcome in women with a history of recurrent miscarriage: a cohort study. Hum Reprod. 2001; 16:102-06. [PubMed: 11139545]

20. REGINALD PW, BEARD RW, CHAPPLE J, et al. Outcome of pregnancies progressing beyond 28 weeks gestation in women with a history of recurrent miscarriage. Br J Obstet Gynaecol. 1987; 94:643-8. [PubMed: 3620412]

21. ANCEL P-Y, LELONG N, PAPIERNIK E, SAUREL-CUBIZOLLES M-J, KAMINSKI M. EUROPOP. History of induced abortion as a risk factor for preterm birth in European countries: results of the EUROPOP survey. Hum Reprod. 2004; 19:734-40. [PubMed: 14998979]

22. FREAK-POLI R, CHAN A, TUCKER G, STREET J. Previous abortion and risk of pre-term birth: a population study. J Matern Fetal Neonatal Med. 2009; 22:1-7. [PubMed: 19085629]

23. LOWIT A, BHATTACHARYA S, BHATTACHARYA S. Obstetric performance following an induced abortion. Best Pract Res Clin Obstet Gynaecol. 2010; 24:667-82. [PubMed: 20362515]

24. VOIGT M, HENRICH W, ZYGMUNT M, FRIESE K, STRAUBE S, BRIESE V. Is induced abortion a risk factor in subsequent pregnancy? J Perinat Med. 2009; 37:144-9. [PubMed: 18976047]

25. CHEN A, YUAN W, MEIRIK O, et al. Mifepristone-induced early abortion and outcome of subsequent wanted pregnancy. Am J Epidemiol. 2004; 160:110-7. [PubMed: 15234931]

26. JACKSON RA, GIBSON KA, WU YW, CROUGHAN MS. Perinatal outcomes in singletons following in vitro fertilization: a meta-analysis. Obstet Gynecol. 2004; 103:551-63. [PubMed: 14990421]

27. BECK I. Incidence of pre-eclampsia in first full-term pregnancies preceded by abortion. J Obstet Gynaecol (Lahore). 1985; 6:82-4. [PubMed: 12314369]

28. ESKENAZI B, FENSTER L, SIDNEY S. A multivariate analysis of risk factors for preeclampsia. JAMA. 1991; 266:237-41. [PubMed: 2056625]

29. KOIFMAN A, LEVY A, ZAULAN Y, et al. The clinical significance of bleeding during the second trimester of pregnancy. Arch Gynecol Obstet. 2008; 278:47-51. [PubMed: 18066562]

30. SEIDMAN DS, EVER-HADANI P, STEVENSON DK, GALE R. The effect of abortion on the incidence of pre-eclampsia. Eur J Obstet Gynecol Reprod Biol. 1989; 33:109-14. [PubMed: 2583336]

31. ZHU Q-X, GAO E-S, CHEN A-M, LUO L, CHENG Y-M, YUAN W. Mifepristone-induced abortion and placental complications in subsequent pregnancy. Hum Reprod. 2009; 24:315-9. [PubMed: 19054774]

32. STONE JL, LOCKWOOD CJ, BERKOWITZ GS, ALVAREZ M, LAPINSKI R, BERKOWITZ RL. Risk factors for severe preeclampsia. Obstet Gynecol. 1994; 83:357-61. [PubMed: 8127525] 
33. CAMPBELL DM, MACGILLIVRAY I, CARR-HILL R. Pre-eclampsia in second pregnancy. Br J Obstet Gynaecol. 1985; 92:131-40. [PubMed: 3970893]

34. SHAH PS. KNOWLEDGE SYNTHESIS GROUP ON DETERMINANTS OF LBW/PT BIRTHS. Parity and low birth weight and preterm birth: a systematic review and meta-analyses. Acta Obstet Gynecol Scand. 2010; 89:862-75. [PubMed: 20583931]

35. FU H, DARROCH JE, HENSHAW SK, KOLB E. Measuring the extent of abortion underreporting in the 1995 National Survey of Family Growth. Fam Plann Perspect. 1998; 30:128-33. 38. [PubMed: 9635261]

36. BHATTACHARYA S, LOWIT A, BHATTACHARYA S, et al. Reproductive outcomes following induced abortion: a national register-based cohort study in Scotland. BMJ open. 2012:2.

37. EDLOW AG, SRINIVAS SK, ELOVITZ MA. Second-trimester loss and subsequent pregnancy outcomes: What is the real risk? Am J Obstet Gynecol. 2007; 197:581.e1-6. [PubMed: 18060941]

38. GOLDENBERG RL, MAYBERRY SK, COPPER RL, DUBARD MB, HAUTH JC. Pregnancy outcome following a second-trimester loss. Obstet Gynecol. 1993; 81:444-6. [PubMed: 8437803]

\section{Appendix}

\section{Appendix}

In addition to the authors, other members of the Eunice Kennedy Shriver National Institute of Child Health and Human Development Maternal-Fetal Medicine Units Network are as follows:

University of Texas Medical Branch, Galveston, TX - G. Saade, J. Moss, B. Stratton, G. Hankins, J. Brandon, C. Nelson-Becker, G. Olson, L. Pacheco

University of Pittsburgh, Pittsburgh, PA - S. Caritis, T. Kamon, M. Cotroneo, D. Fischer

University of Utah, Salt Lake City, UT - P. Reed, R. Silver, K. Hill (University of Utah), S. Quinn, F. Porter (LDS Hospital), V. Morby (McKay-Dee Hospital), J. Miller (Utah Valley Regional Medical Center)

University of Alabama at Birmingham, Birmingham, AL - D.J. Rouse, A. Northen, P. Files, J. Grant, M. Wallace, K. Bailey

Columbia University, New York, NY - R. Wapner, S. Bousleiman, R. Alcon, K. Saravia, F. Loffredo, A. Bayless (Christiana), C. Perez (St. Peter's University Hospital), M. Lake (St. Peter's University Hospital), M. Talucci

University of North Carolina at Chapel Hill, Chapel Hill, NC - K. Boggess, K. Dorman, J. Mitchell, K. Clark, S. Timlin

Case Western Reserve University-MetroHealth Medical Center, Cleveland, OH - J. Bailit, C. Milluzzi, W. Dalton, C. Brezine, D. Bazzo

University of Texas Southwestern Medical Center, Dallas, TX - J. Sheffield, L. Moseley, M. Santillan, K. Buentipo, J. Price, L. Sherman, C. Melton, Y. Gloria-McCutchen, B. Espino 
Northwestern University, Chicago, IL - M. Dinsmoor (NorthShore University

HealthSystem), T. Matson-Manning, G. Mallett

University of Texas Health Science Center at Houston, Houston, TX - S. Blackwell, K.

Cannon, S. Lege-Humbert, Z. Spears

Brown University, Providence, RI - M. Carpenter, J. Tillinghast, M. Seebeck The Ohio

State University, Columbus, OH - P. Samuels, F. Johnson, S. Fyffe, C. Latimer, S. Frantz, S. Wylie

Drexel University, Philadelphia, PA - M. Talucci, M. Hoffman (Christiana), J. Benson (Christiana), Z. Reid, C. Tocci

Wake Forest University Health Sciences, Winston-Salem, NC - M. Harper, P. Meis, M. Swain

Oregon Health \& Science University, Portland, OR - W. Smith, L. Davis, E. Lairson, S. Butcher, S. Maxwell, D. Fisher

Wayne State University, Detroit, MI - G. Norman, S. Blackwell, P. Lockhart, D. Driscoll, M. Dombrowski

The George Washington University Biostatistics Center, Washington, DC - E. Thom, T. Boekhoudt, L. Leuchtenburg

National Heart, Lung, and Blood Institute, Bethesda, MD - G. Pearson, V. Pemberton, J. Cutler, W. Barouch

Eunice Kennedy Shriver National Institute of Child Health and Human Development, Bethesda, MD - S. Tolivaisa

MFMU Steering Committee Chair (University of Texas Medical Center, Galveston, TX) G.D. Anderson 
Table 1

Demographics and Baseline Characteristics

\begin{tabular}{|c|c|c|c|c|}
\hline & Primigravid (N=7681) & One or more SABs $(N=1240)$ & One or more IABs ( $N=817)$ & $\mathbf{P}$ \\
\hline Treatment group & & & & 0.6 \\
\hline Placebo & $3827(49.8)$ & $610(49.2)$ & $420(51.4)$ & \\
\hline Vitamins & $3854(50.2)$ & $630(50.8)$ & $397(48.6)$ & \\
\hline Tobacco use & $1057(13.8)$ & $225(18.1)$ & $211(25.8)$ & $<0.0001$ \\
\hline Married & $3370(43.9)$ & $556(44.8)$ & $233(28.5)$ & $<0.0001$ \\
\hline Race & & & & $<0.0001$ \\
\hline African American & $1839(23.9)$ & $321(25.9)$ & $288(35.3)$ & \\
\hline Hispanic & $2475(32.2)$ & $377(30.4)$ & $174(21.3)$ & \\
\hline Caucasian/Other & $3367(43.8)$ & $542(43.7)$ & $355(43.5)$ & \\
\hline Maternal age & $23.1 \pm 5.0$ & $24.5 \pm 5.5$ & $25.0 \pm 5.6$ & $<0.0001$ \\
\hline Total years of schooling & $12.7 \pm 2.8$ & $12.7 \pm 2.7$ & $13.5 \pm 2.1$ & $<0.0001$ \\
\hline BMI at enrollment & $26.1 \pm 6.0$ & $27.0 \pm 6.6$ & $26.4 \pm 5.9$ & $<0.0001$ \\
\hline GA at enrollment (weeks) & $13.4 \pm 2.1$ & $13.3 \pm 2.1$ & $13.3 \pm 2.2$ & 0.07 \\
\hline
\end{tabular}

Data represented as N (Percent) or Mean \pm S. D.

$\mathrm{SAB}=$ spontaneous abortion, $\mathrm{IAB}=$ induced abortion, $\mathrm{BMI}=$ body mass index, $\mathrm{GA}=$ gestational age 
Table 2

Multivariable analysis of maternal and fetal outcomes in subjects with history of one or multiple SABs.

\begin{tabular}{|l|c|c|c|}
\hline Outcome & Primigravid (N=7681) & One SAB (N=1060) & Two or More SABs (N=180) \\
\hline Spontaneous preterm birth $^{*}$ & $438(5.8)$ & $58(5.6)$ & $\mathbf{2 5}(\mathbf{1 4 . 4 )}$ \\
& & $1.0[0.7-1.3]$ & $\mathbf{2 . 6}[\mathbf{1 . 7 - 4 . 0}]$ \\
\hline Indicated preterm birth $^{*}$ & $231(3.0)$ & $35(3.4)$ & $6(3.4)$ \\
& & $1.1[0.7-1.5]$ & $1.0[0.4-2.4]$ \\
\hline Preterm PROM & $172(2.3)$ & $23(2.2)$ & $\mathbf{1 3}(\mathbf{7 . 3})$ \\
& & $0.9[0.6-1.4]$ & $\mathbf{2 . 9}[\mathbf{1 . 6 - 5 . 3}]$ \\
\hline Pre-eclampsia & $539(7.0)$ & $74(7.0)$ & $9(5.0)$ \\
& & $1.0[0.7-1.2]$ & $0.6[0.3-1.2]$ \\
\hline Fetal/Neonatal death & $157(2.1)$ & $\mathbf{3 5}(\mathbf{3 . 3})$ & $\mathbf{1 2}(\mathbf{6 . 7})$ \\
& & $\mathbf{1 . 5}[\mathbf{1 . 1}-\mathbf{2 . 3}]$ & $\mathbf{2 . 8}[\mathbf{1 . 5}-\mathbf{5 . 3}]$ \\
\hline Birthweight < 5th percentile & $371(4.9)$ & $48(4.7)$ & $\mathbf{1 7}(\mathbf{9 . 9})$ \\
& & $1.0[0.7-1.3]$ & $\mathbf{2 . 2}[\mathbf{1 . 3}-\mathbf{3 . 7}]$ \\
\hline Neonatal intensive care admission & $861(11.2)$ & $110(10.4)$ & $27(15.1)$ \\
& & $0.9[0.7-1.1]$ & $1.2[0.8-1.8]$ \\
\hline
\end{tabular}

Data shown are number of outcomes (percent)

Odds ratio compared to the primigravid group [95\% confidence interval] were calculated after adjusting for maternal age, race, education, smoking, marital status, BMI at enrollment, and study drug (placebo or vitamin C and E). Odds ratio in bold typeface are statistically significant.

$\mathrm{SAB}=$ spontaneous abortion, $\mathrm{PROM}=$ premature rupture of membranes

*

Excludes 110 women whose current pregnancy resulted in SAB or IAB (87 primigravid, 17 one SAB, 6 two or more SABs). 
Table 3

Multivariable analysis of maternal and fetal outcomes in subjects with history of one or multiple IABs.

\begin{tabular}{|l|c|c|c|}
\hline Outcome & Primigravid (N=7681) & One IAB (N=642) & Two or More IABs (N=175) \\
\hline Spontaneous preterm birth $^{*}$ & $438(5.8)$ & $\mathbf{5 2}(\mathbf{8 . 2})$ & $16(9.3)$ \\
& & $\mathbf{1 . 4}[\mathbf{1 . 0 - 1 . 9}]$ & $1.6[1.0-2.8]$ \\
\hline Indicated preterm birth $^{*}$ & $231(3.0)$ & $22(3.5)$ & $5(2.9)$ \\
& & $1.1[0.7-1.7]$ & $0.9[0.3-2.1]$ \\
\hline Preterm PROM & $172(2.3)$ & $\mathbf{3 1 ( 4 . 9 )}$ & $8(4.7)$ \\
& & $\mathbf{2 . 0}[\mathbf{1 . 4 - 3 . 0}]$ & $1.8[0.9-3.8]$ \\
\hline Pre-eclampsia & $539(7.0)$ & $41(6.4)$ & $13(7.4)$ \\
& & $0.9[0.7-1.3]$ & $1.1[0.6-1.9]$ \\
\hline Fetal/Neonatal death & $157(2.1)$ & $17(2.7)$ & $7(4.0)$ \\
& & $1.2[0.7-2.0]$ & $1.7[0.8-3.8]$ \\
\hline Birthweight < 5th percentile & $371(4.9)$ & $22(3.5)$ & $\mathbf{2}(\mathbf{1 . 2})$ \\
& & $0.7[0.5-1.1]$ & $\mathbf{0 . 2}[\mathbf{0 . 1}-\mathbf{1 . 0}]$ \\
\hline Neonatal intensive care admission & $861(11.2)$ & $79(12.3)$ & $22(12.6)$ \\
& & $1.1[0.8-1.4]$ & $1.1[0.7-1.7]$ \\
\hline
\end{tabular}

Data shown are number of outcomes (percent)

Odds ratio compared to the primigravid group [95\% confidence interval] were calculated after adjusting for maternal age, race, education, smoking, marital status, BMI at enrollment, and study drug (placebo or vitamin C and E). Odds ratio in bold typeface are statistically significant.

$\mathrm{IAB}=$ induced abortion, $\mathrm{PROM}=$ premature rupture of membranes

*

Excludes 97 women whose current pregnancy resulted in SAB or IAB (87 primigravid, 7 one IAB, 3 two or more IABs). 


\section{Table 4}

Multivariable analysis of maternal and fetal outcomes in subjects with history of one SAB based on interpregnancy interval.

\begin{tabular}{|l|c|c|c|}
\hline Outcome & Less than 6 months (N=395) & $\mathbf{6 - 1 2}$ months (N=216) & Greater than 12 months (N=429) \\
\hline Spontaneous preterm birth $^{*}$ & $17(4.4)$ & $15(7.0)$ & $24(5.7)$ \\
& & $1.6[0.8-3.4]$ & $1.2[0.6-2.3]$ \\
\hline Indicated preterm birth $^{*}$ & $14(3.6)$ & $4(1.9)$ & $17(4.0)$ \\
& & $0.5[0.2-1.5]$ & $0.9[0.4-2.0]$ \\
\hline Preterm PROM & $6(1.5)$ & $\mathbf{1 1}(\mathbf{5 . 2})$ & $5(1.2)$ \\
& $31(7.8)$ & $11(5.1)$ & $0.8[0.2-2.8]$ \\
\hline Pre-eclampsia & $13(3.3)$ & $0.6[0.3-1.2]$ & $31(7.2)$ \\
& & $6(2.8)$ & $0.8[0.4-1.3]$ \\
\hline Fetal/Neonatal death & $20(5.2)$ & $0.7[0.3-2.0]$ & $16(3.8)$ \\
& & $6(2.8)$ & $0.8[0.3-1.7]$ \\
\hline Birthweight < 5th percentile & $43(10.9)$ & $0.5[0.2-1.2]$ & $22(5.3)$ \\
& & $0.6[0.3-1.1]$ & $0.9[0.5-1.7]$ \\
\hline Neonatal intensive care admission & & & $50(11.7)$ \\
& & & $0.9[0.6-1.4]$ \\
\hline
\end{tabular}

Data shown are number of outcomes (percent)

Odds ratio compared to the less than 6 months group [95\% confidence interval] were calculated after adjusting for maternal age, race, education, smoking, marital status, BMI at enrollment, and study drug (placebo or vitamin C and E). Odds ratio in bold typeface are statistically significant.

$\mathrm{SAB}=$ spontaneous abortion, $\mathrm{PROM}=$ premature rupture of membranes

Excludes 17 women whose current pregnancy resulted in SAB or IAB. 